\title{
Developing a Candidate Registration System for Zambia School Examinations using the Cloud Model
}

\author{
Banji Milumbe, Jackson Phiri, Monica M Kalumbilo, Mayumbo Nyirenda \\ Department of Computer Science \\ The University of Zambia \\ Lusaka, Zambia
}

\begin{abstract}
Cloud computing has in the recent past gained a lot of ground in this digital age. The use of cloud technologies in business has broken barriers in sharing information making the world one big global village. Regardless of where one is, data or information can be received or sent instantly disregarding distance. In this research, we investigated the challenges in registering candidates for school examinations and availability of internet services in various parts of Zambia and then present a candidate registration process based on the cloud model which is aimed at resolving challenges of distances from examination centres to the examining body in order to register for examinations as well as improving the timelines and cutting down the back and forth movements in the whole process. The web based registration system was developed and tested and the testing ascertained connectivity, functionality and scalability of the system.
\end{abstract}

Keywords-Cloud computing; candidate registration; online registration; Zambia; school examinations; bulk SMS; automation; information communication technology; ICT

\section{INTRODUCTION}

In this digital age, the advancements in technology have changed the way businesses operate. The proper, planned use of ICT can be highly beneficial but the fact of using ICT does not of itself automatically bring benefits [1]. The internet has made work easier in that one can access different facilities anywhere anytime, opening up numerous possibilities for doing business at a local and global level. Applications are being developed that enable information to be received in realtime regardless of the user's location. The availability of candidates information in good time would help examining bodies that conduct public examinations to adequately prepare accurate examination materials and reduce on errors.

The Examinations Council of Zambia (ECZ) created by an Act of Parliament Number 15 of 1983 whose main purpose was to set and conduct examinations and award certificates to successful candidates in Zambia. Its full launch and operationalisation was in 1987 as a semi-autonomous public institution [2]-[4]. Ten (10) years later, ECZ embarked on automating systems and localised the results processing as well as registration of candidates for school examinations. Different methods of getting candidates data for examinations were used starting from manual systems to some electronic systems which proved to have posed challenges in the accuracy, efficiency and effectiveness of such systems [5]. In the latest candidate registration method described by [6] was used by ECZ where examination centres were every year be provided with a CD containing the desktop candidate registration application. All Centres with prospective candidates for examinations would enter the candidate details and then create a text file of candidate details in a predetermined format which was later submitted to ECZ. This research investigated the candidate registration for school examinations in Zambia in order to develop a candidate registration system that utilises cloud services.

\section{LITERATURE REVIEW}

\section{A. Introduction}

The internet has become an invaluable and integral part of business and personal life in the modern world [1]. The rapid development of processing and storage technologies and success of the internet, have made computing resources become cheaper, more powerful and more available than ever before. This technological trend has enabled the realisation of a new computing model called cloud computing, in which resources are provided as general utilities that can be leased and released by users through the internet in an on demand style [7]. Internet has created a technology innovation, a new digital market place, rendering the need for centralised cloud service unavoidable [8]-[12]. While the enterprise begins to embrace the internet of things via the ability to communicate more digitally, the promises of business improvement at a reduced shared cost is leaking quietly.

Many sectors like governmental, non-governmental, profit and non-profit organisations have taken advantage of these technological developments to improve the way business is conducted and be up to speed with the rest of the world. In the education sector, many technologies have been adopted to enhance learning, teaching and also in the area of capturing and storing student information.

\section{B. ICTs in the Education Sector}

The prospects for the utilisation of new technologies in the field of education continue to be part of the transformations in the education sector with a strong bearing on the assessment and evaluation of the education system in public examinations. In a study conducted by Sibanda and Maposa, 2013 it was established that ICT can be utilised as an integral component to improve efficiency, effectiveness and excellence in learning, teaching and assessment [13]. Automated systems as alluded to by Obioma et al., 2013 offer some benefits in the education sector such as; lower long-term costs, instant feedback to students, creation of digital records of student growth and 
development, greater storage efficiency and increased productivity and low operational variability [14]. Employing new technology in any project implies certain inherent risks, so an adequate technology management is a precondition for a successful software development project [15].

\section{Cloud Computing}

Computing is being transformed to a model consisting of services that are commoditised and delivered in a manner similar to utilities such as water, electricity, gas, and telephony. In such a model, users access services based on their requirements regardless of where the services are hosted. Several computing paradigms have promised to deliver this utility computing vision [16]. Cloud computing has been defined by its characteristics by Buyya as follows, 'Cloud computing is a parallel and distributed system consisting of a collection of inter-connected and virtualised computers that are dynamically provisioned and presented as one or more unified computing resources based on service-level agreements (SLA) established through negotiation between the service provider and consumers' [7].

Cloud computing has the potential to dramatically change business models and the way people interact with each other because it provides access to large-scale remote resources in a very efficient and quick manner. It has the potential to level the playing field because it breaks barriers to entry [17]. Cloud computing is thought to be the solution to overcome the problem of processing large amounts of data. By using cloud computing the cost of implementing software solutions and storage of data is reduced significantly [18]. Using cloud based storage for large amounts of data is the key [19].

\section{Web Applications Integrated with Bulk Short Message \\ Service (SMS)}

The wide use of mobile telecommunications has also brought about the integration of web based systems with mobile telecommunications especially with the GSM being the most successful digital mobile telecommunications used by millions of people in various countries in the world [20].

Use of mobile phone helps to have access to the system or receive alerts from the systems via mobile phone even when you are not connected to the internet. A useful service for very simple message transfer is the short message service (SMS), which can be used for "serious" applications as noted by [20].

A study conducted by [21] where use of SMS/USSD was proposed proved to be faster and more reliable in disseminating information on examination registration and results to candidates than the traditional computer.

\section{METHODOLOGY AND SCOPE}

This study was conducted in all the ten (10) provinces of Zambia comprising provincial and district education offices and schools out of which $75 \%$ were secondary schools and $25 \%$ primary schools. The rationale behind having this proportion of schools was that secondary schools conduct up to three (3) different examinations per year while primary schools mainly conduct only one examination in a year. Nonprobability sampling technique was used in this study for the
122 study participants by virtue of their specialised knowledge in the subject area.

The purpose of the baseline study was to establish the challenges with the registration of candidates and availability of internet services in the provinces. The questionnaires and interview guide were used to gather the data for this research. The results from the study were used as input or part of requirements gathering for the web based registration system. It also helped to ascertain the feasibility of implementing a web based registration solution in all examination registration centers in Zambia.

\section{A. System Automation}

Results of the baseline study and the regulations on registration for examinations in Zambia [22] were used to design a registration model based on cloud technologies.

The Web based candidate registration system that utilises the cloud model and integrates bulk SMS as well as barcode technology is shown in Fig. 1. The registration takes place at the examination centre after receiving notification through the integrated bulk SMS system that registration had begun. The Province and District users monitor the registration process by logging in the system, they are being able to view and generate statistical reports on the candidates registered. The integrated barcode technology in the system is to issue a card with a barcode containing candidate details which can be used during examinations and any other subsequent registrations for examinations.

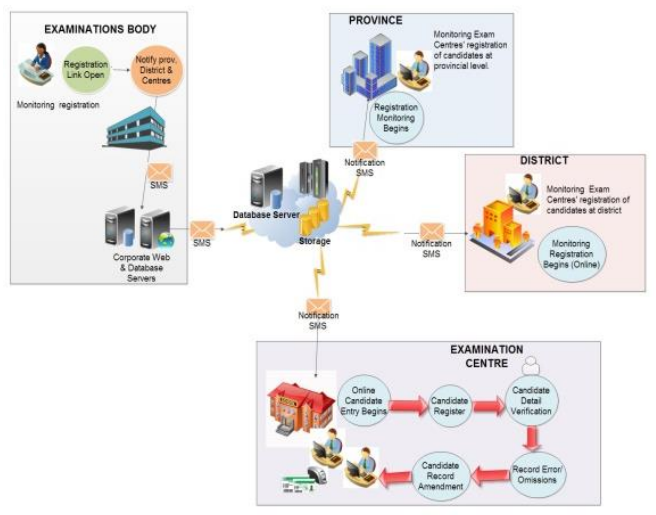

Fig. 1. Web based candidate registration model.

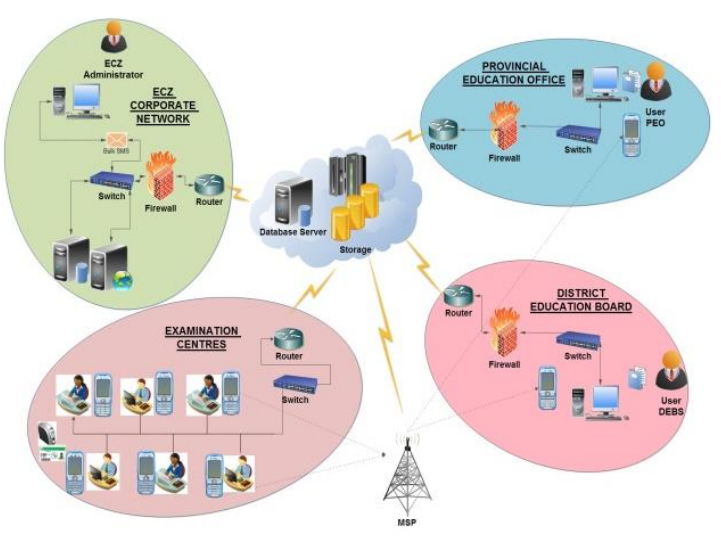

Fig. 2. Web based candidate registration system for ECZ. 


\section{B. System Architecture}

The diagrammatic representation of the system architecture of the Web based Candidate Registration System (WCRS) for ECZ is shown in Fig. 2.

The architecture has the following components comprising the ECZ corporate network where the administrator opens the registration link and bulk SMS sent to all provinces, districts and Examination centre coordinators to inform them that the registration had opened. The other local networks are at the provincial education office, District Education board secretary's office and the examination centres, the cloud service constituting database storage and user application. The local service constituting database storage and user application as a backup measure is located at ECZ HQ. The Mobile Service Provider which is integrated with the web based application for sending and receiving the SMS is included.

As shown in Fig. 2, the system administrator at ECZ sends an SMS to all concerned parties in the registration process so that they could begin the registration. The web based candidate registration system is accessed using a web browser. The local backup server also exists as a backup measure in case of failures in the cloud. The local and cloud servers constantly synchronize to ensure data integrity and completeness

\section{System Modelling and Design}

The Unified Modelling Language (UML) was used to come up with Use case diagram. The use case diagram was developed based on the information gathered to incorporate the main actors in the candidate registration system like the system administrator and the user (Guidance Teacher). Fig. 3 shows the different actions that the System Administrator does with the system.

\section{Sequence Diagram}

The sequence diagram in Fig. 4 shows the business processes for the guidance teacher (user) in the system.

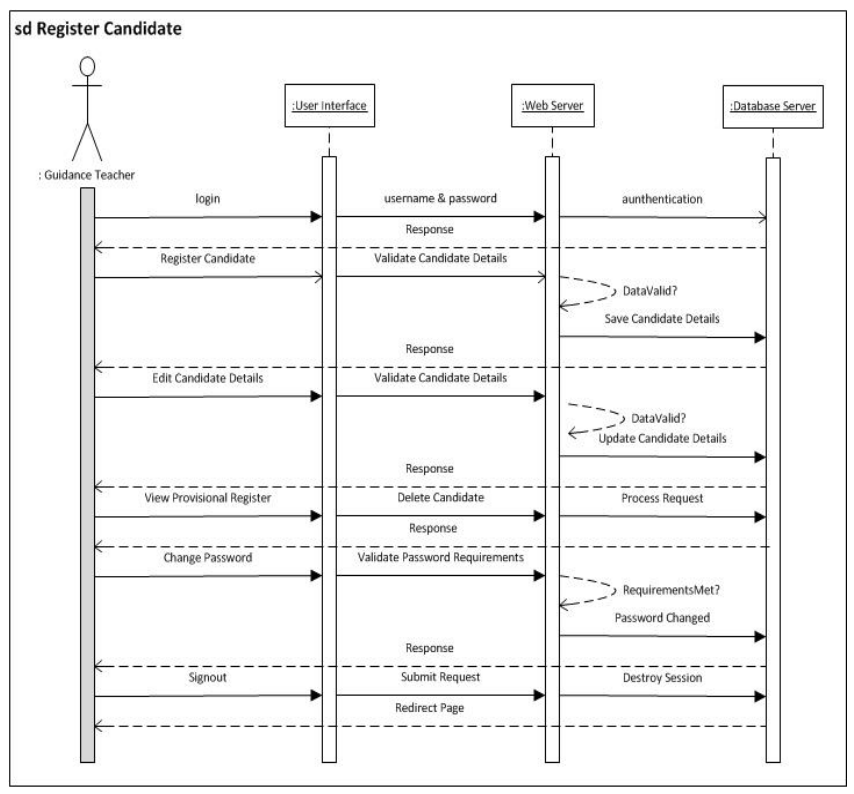

Fig. 3. System administrator activities use case diagrams.

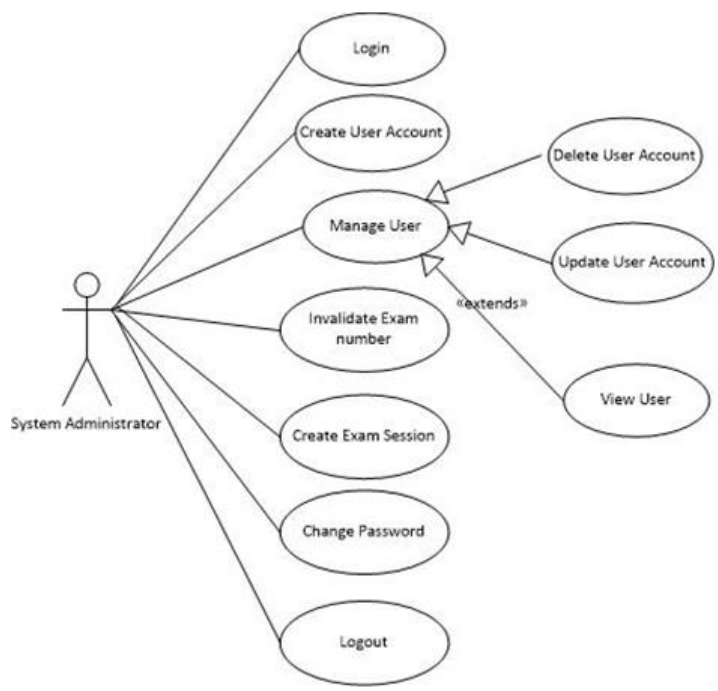

Fig. 4. Guidance teacher (user) sequence diagram.

\section{RESULTS}

The focus of the study was to also establish that there was adequate infrastructure to deploy a web based candidate registration system in the various locations across the country. The results presented are derived from the responses by the respondents after data analysis.

\section{1) Baseline study}

The data collected was analysed and the results of the baseline study are presented in this section using charts.

\section{a) Internet Accessibility}

The research findings confirmed that internet was available and accessible through different means as indicated in Fig. 5. The following were the ways in which the 122 respondents access internet. Eighty (80) percent access internet through their personal mobile devices, like phones, tablets or dongles, 17 per cent said they accessed internet from their work place which was provided by their employers, while 1 per cent said that they access internet through public wifi like iconnect, iZone or wifi at shopping malls and 2 per cent said they accessed it through internet cafes. This means that people have access to internet services.

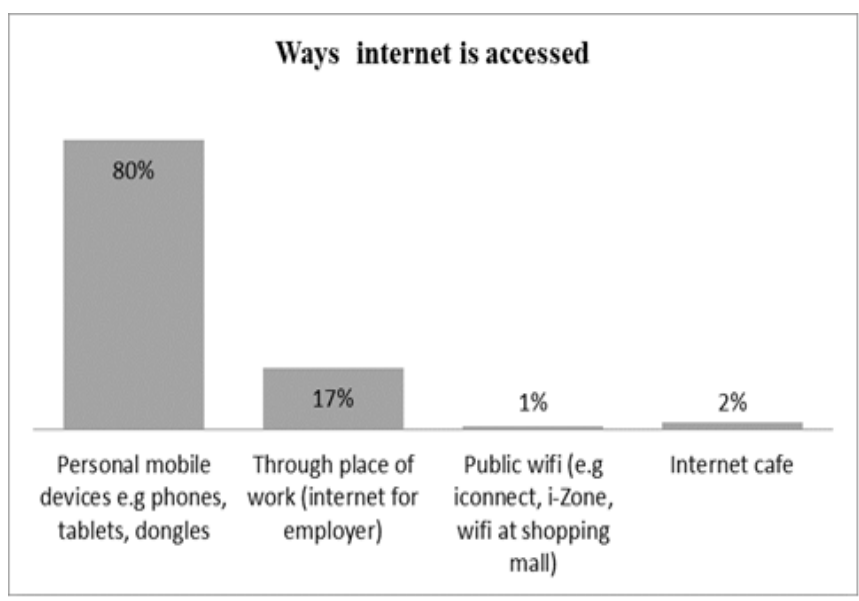

Fig. 5. Ways internet is accessed. 


\section{b) Availability of Mobile phone service}

The participants also indicated the mobile network available in their area. The pie chart in Fig. 6 shows that there is at least one mobile service provider in the area making it possible to for them to have access to internet services via the mobile service providers. Information about the availability of mobile service providers was important because most of the access to internet is through these mobile service providers.

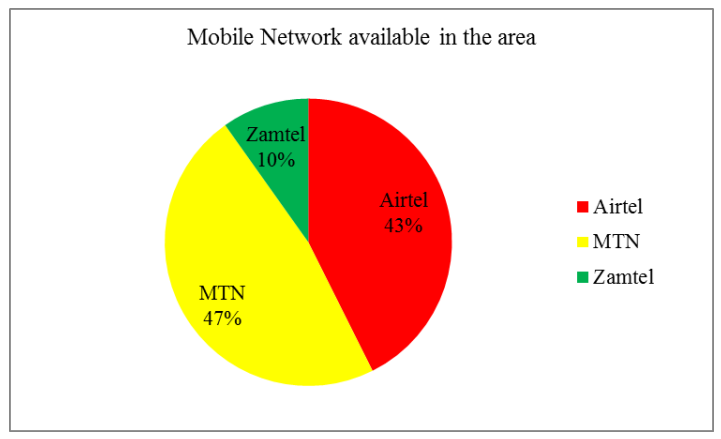

Fig. 6. Mobile service provider available.

\section{application}

c) Benefits of a web based candidate registration

Benefits of a web based registration system were established and from the findings, it was clear that a web based candidate registration system was highly recommended. The reasons why respondents recommend a web-based system are indicated in Fig. 7 such as it being faster, efficient and effective, very convenient and many others.

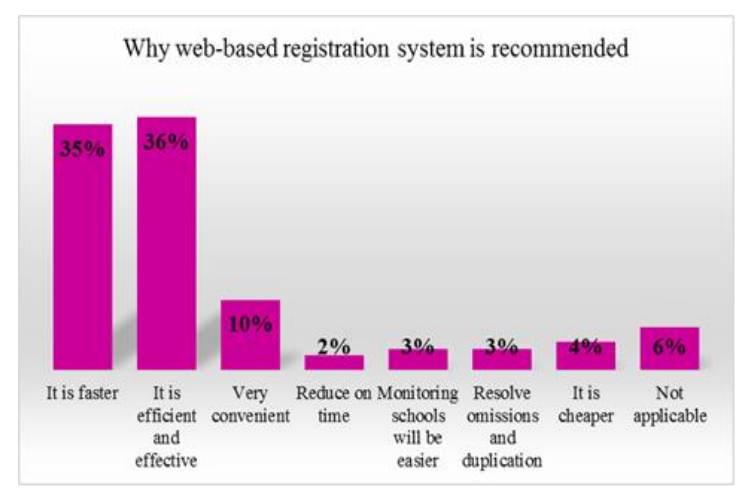

Fig. 7. Perceived benefits of a web application.

\section{System DEVElopment AND TESTING}

The system was successfully developed and tested.

\section{A. System Development}

A representation of some screen shots of the developed system is shown.

1) Administrator login and user creation: The system administrator is responsible for managing users in the system. For a user to be able to access the web based system modules, they must be registered in the system. All the data entered into the system should be traced to the user that entered. The administrator log in shown in Fig. 8 is to enable create a new user account in the system.

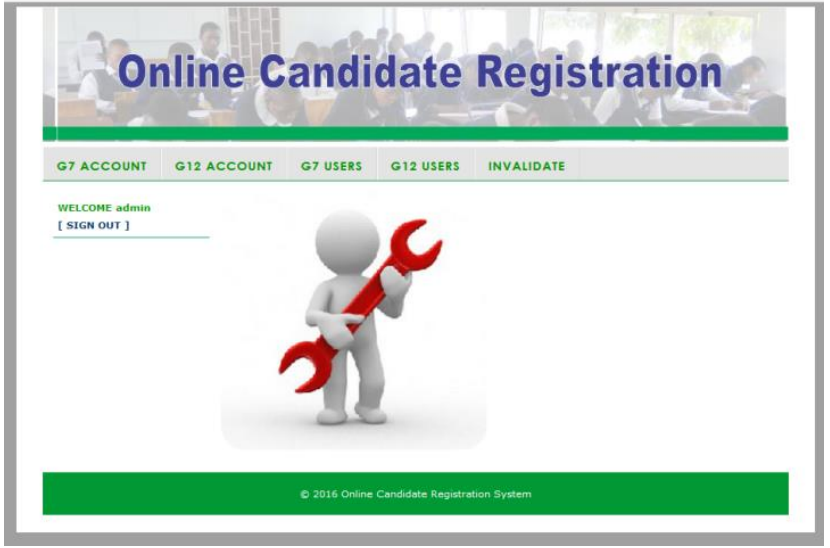

Fig. 8. Administrator sign in home page.

2) Registering a candidate: To register a candidate, you login to the appropriate level or grade and select the correct centre details. A candidate's examination number is automatically generated and the user can enter all the candidate details as shown in Fig. 9. Once the details have been entered, proceed to select subjects and then complete registration as shown in Fig. 10.

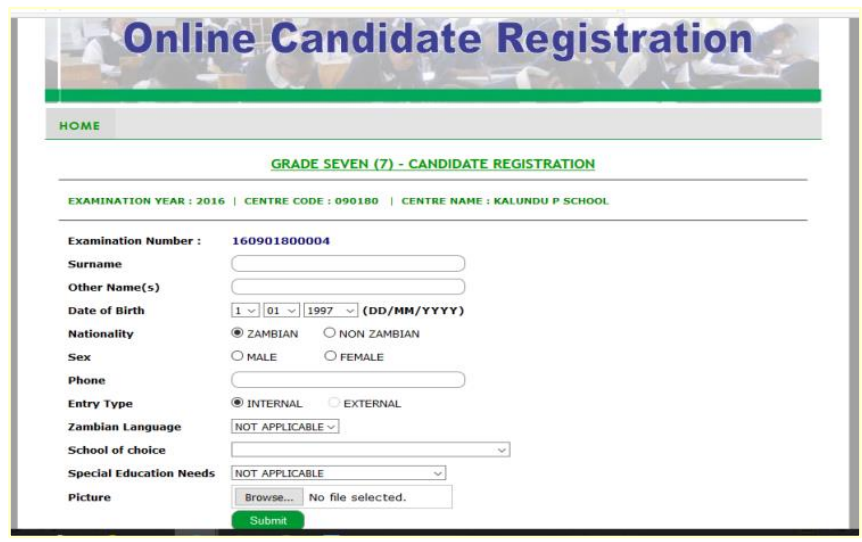

Fig. 9. Candidate entry details screen.

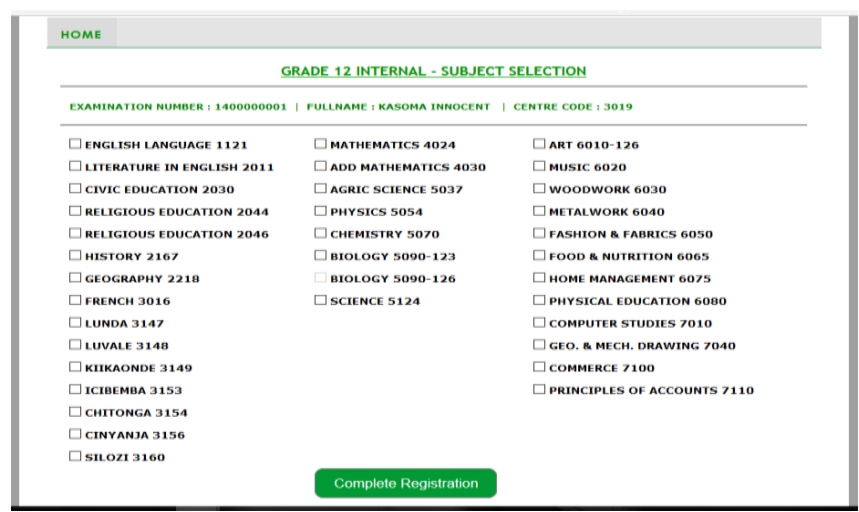

Fig. 10. Subjects selection.

3) Reports menu: The web based candidate registration system has several reports that can be generated by the user as shown in Fig. 11. 


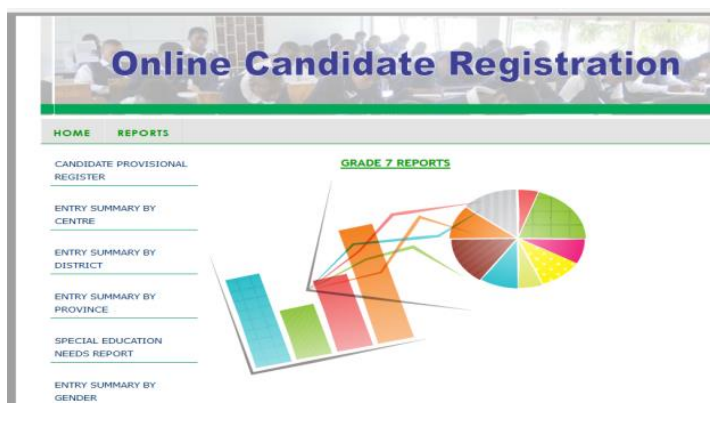

Fig. 11. Reports selection.

\section{B. System Testing}

The testing of the web based candidate registration system was undertaken to verify connectivity to the application, functionality and scalability.

1) Test sample: The test sample comprised 40 schools, two (2) from each selected district from the ten (10) provinces. Of the schools and districts selected, there was a balance between rural and urban districts and schools. Fifty (50) candidates were selected in each of the schools to be registered using the web based candidate registration system.

2) Testing results: Out of 40 schools selected for testing the system, 39 schools were used as test centres and all the 39 could access the web application, able to update candidate details and tested the various reports. Thirty six out of thirtynine $(92 \%)$ schools successfully registered all the 50 candidates sampled while three centres could not register all the 50 due to wrong examination numbers of the sampled candidates. Thus, the system could not retrieve candidate details to proceed with registration. This was part of testing the system as well to those conditions /rules as successfully applied.

3) Tools used for testing: During the system testing, laptops, mobile devices like tablets or mobile phones and mobile wireless 3G Routers were used in testing for the internet connectivity. The testing relied solely on the mobile phone service providers available in each area/school for internet connectivity. Even though the school had its own internet connection, it was not used because the testing wanted to establish availability of internet connectivity so that even schools that did not have internet of their own could easily purchase similar routers/modems and be able to access the web based registration system to register candidates.

4) Testing internet connectivity: The internet connection speed was tested at each of the schools where the pilot was conducted using the online website speed tester, www.speed.io. The download and upload speed was recorded as it showed under measured data of the online speed tester. The download speed ranged from $1.527 \mathrm{~kb} / \mathrm{s}$ to $8972 \mathrm{~kb} / \mathrm{s}$ while the upload speed ranged from $2 \mathrm{~kb} / \mathrm{s}$ to $506 \mathrm{~kb} / \mathrm{s}$. The time of testing the connection speed also had a bearing on the connection speed as at certain times some places were congested while in other places there was little congestion and the internet connection speed was very fast.
Fig. 12 shows that internet connectivity was available in all the schools that were used as sites for system testing both rural and urban schools. In each of these schools there was at least one mobile network provider available and internet access was possible using the $3 \mathrm{G}$ wireless modems for internet service. It should be noted though that in one of the centres, internet could only be accessed at a particular point which was under a guava tree. Despite that however, registration of candidates using the web based application system was successful.

5) System Performance and responsive: It was noted that the system response during the testing was good in most of the schools which accounted for 95 percent while 5 percent said it was fair. None of the test sites recorded poor system response which showed that the web based registration system generally performed very well.

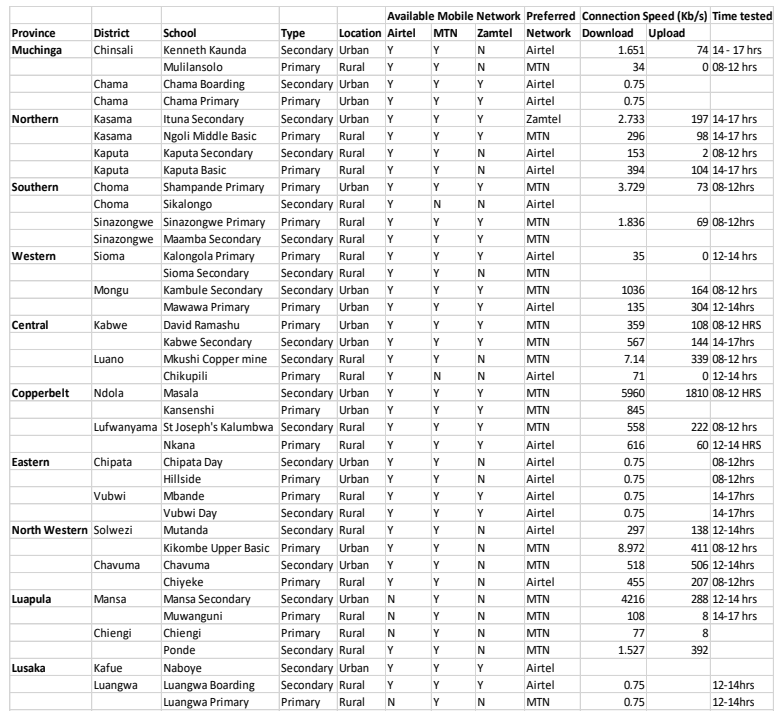

Fig. 12. Summary results of connectivity test.

\section{CONCLUSION AND FUTURE SCOPE}

The study brought out important points on the availability and use of internet in various parts of the country, both rural and urban areas. This helped to ascertain that the web based candidate registration would be used without much difficulty in all schools to register candidates for school examinations.

The system test results validated the web based registration system and the next stage was to fully develop the system and use it at full scale for registration of candidates for school examinations in Zambia. The proposed web system would cut down on some unnecessary processes thereby reducing the time it takes to complete the candidate registration process.

The system only has one level of user authentication. The second level user authentication for using biometrics should be for future inclusion in addition to the use of CCTV in the registration rooms and GPS/GIS Location to enhance the security of the system in the cloud. An alternative fully fledged mobile application for popular and affordable mobile devices such as those that use the Android operating system should be provided in future. 


\section{ACKNOWLEDGMENT}

We are grateful to the Director, Examinations Council of Zambia for allowing us to carry out this research at the Institution, ECZ employees and the Provincial Education Offices for assisting us in collecting data from Schools and Districts.

\section{REFERENCES}

[1] T. Lucey, Management Information Systems, 9th ed., London: BookPower, 2005.

[2] ECZ, "Examinations Council of Zambia Strategic Plan for 2009 to 2015," Examinations Council of Zambia, Lusaka, 2009.

[3] Zambia, Laws of Zambia. Examinations Council of Zambia Act Cap 137 of 1983. Lusaka, Lusaka: Zambian Parliament, 1983.

[4] M. J. Kelly, "Education in a Declining Economy," World Bank, Washington DC, 1991.

[5] Banji M. Shakubanza and Joe Kanyika, "Innovative Technologies in Enhancing Performance in the Conduct of Public Examinations: A Reflection on the Examinations Council of Zambia," Journal of the Association for Educational Assessment in Africa, vol. 5, pp. 163-175, 2011.

[6] Banji Milumbe, "Automation of the Candidate Registration for School Examinations in Zambia using the Cloud Model," in Proceedings of the IEEE International Conference in Information and Communication Technologies (ICICT)", Lusaka, pp. 108-115, 2017.

[7] M.G. Avram Olaru, "Advantages and challenges of adopting cloud computing from an enterprise perspective," Procedia Technology, vol. 12, pp. 529-534, 2014.

[8] T. U. Daim, "Exploring technology acceptance for online food services," International Journal of Business Information Systems, vol. 12, no. 4, pp. 383-403, 2013.

[9] A. Antonov, "New business-oriented global/regional information network," International Journal of Business Information Systems, vol. 12, no. 3, pp. 321-334, 2013.

[10] B. Gannon, "Outsiders: an exploratory history of IS in corporation," Journal of Information Technology, vol. 28, no. 1, pp. 50-62, 2013.
[11] W. Venters and E. A. Whitley, "A critical review of cloud computing: researching desires and realities," Journal of Information Technology, vol. 20, no. 1, pp. 113-126, 2012.

[12] A. Abareshi, W. Martin and A. Molla, "The role of information and communication technologies in moving toward new forms of organising," International Journal of Business Information Systems, vol. 9, no. 2, pp. 169-188, 2012.

[13] F. Sibanda and R. S. Maposa, "The Ethics of ICT Assessment in Public Examinations: Reflections on the Zimbabwean Experience," International Journal of Academic Research in Progressive Education and Development, vol. 2, no. 1, pp. 94-99, January 2013.

[14] G. Obioma, I. Junaidu and G. Ajagun, "The Automation of Educational Assessment in Nigeria: Challenges and implications for pre-service Teacher Education," in Paper presented at the Annual Conference of the International Association for Educational Assessment, Tel-Aviv, Israel, 2013.

[15] P. Mangudo, M. Arroqui, C. Marcos and C. Machado, "Rescue of a whole-farm system: crystal clear in action," International Journal of Agile and Extreme Sofware Development, vol. 1, no. 1, pp. 6-22, 2012.

[16] R. Buyya, "Introduction to the IEEE Transactions on Cloud Computing," IEEE Transactions on Cloud Computing, vol. 1, no. 1, pp. 3-21, January-June 2013.

[17] S. Greengard, "Cloud Computing and Developing Nations," Communications of the ACM, vol. 53, no. 5, pp. 18-20, May 2010.

[18] A. A. Tole, "Cloud Computing and Business Intelligence," Database Systems Journal, vol. 5, no. 4, pp. 49-58, 2014.

[19] Mulima Chibuye and Jackson Phiri, "A Remote Sensor Network using Android Things and Cloud Computing for the Food Reserve Agency in Zambia," International Journal of Advanced Computer Science and Applications, vol. 8, no.11, pp. 411-418, 2017.

[20] J. Schiller, Mobile Communications, 2nd ed., London: Addison Wesley, 2003.

[21] Lovemore Solomon and Jackson Phiri, "Enhancing the Administration of National Examinations using Mobile Cloud Technologies: A Case of Malawi National Examinations Board," International Journal of Advanced Computer Science and Applications, vol. 8, no.9, pp. 294305, 2017.

[22] ECZ, 'Guidelines on the Administration and Management of Examinations in Zambia', Examinations Council of Zambia, Lusaka, 2015. 